\title{
BLUEPRINTS FOR CHANGE: WHAT MULTICULTURAL EXPERIENCE OFFERS INSTRUCTORS OF PRE-SERVICE EARLY EDUCATION TEACHERS
}

\author{
Michelle Henault Morrone' ${ }^{1}$ \& Yumi Matsuyama ${ }^{2}$ \\ ${ }^{I}$ Department of Human Care, Nagoya University of Arts and Sciences (Japan) \\ ${ }^{2}$ Nihon Fukushi University (Japan)
}

\begin{abstract}
This research is part of a long-term study focused on the redesign of pre-service early teacher education based on observations of schools that use a multicultural inclusive model. The Swedish school highlighted in this research provides a case study in how international standards are appraised by education stakeholders (researchers, educators, the local community, etc.) and then transformed into curricula in local practice. The key to this Swedish approach is the emphasis on democratic values in education. This gives the educators at the preschool in question a traditional "Swedish" basis for their progressive efforts to rise to the challenges presented by their multicultural student body, challenges they meet by creating a warm and welcoming atmosphere for all members of the school community, students, teachers, and parents alike. The goal is to make each person feel valued and included in the educational process. The emphasis is on inclusivity for all, whatever their background, religion or socio-economic status. The approach of the Ringmuren Forskolan is presented as a potential model for institutions that have the responsibility of preparing pre-service teachers for their work in an increasingly multicultural world.
\end{abstract}

Keywords: Multiculturalism, pre-service, inclusivity, preschool.

\section{Introduction}

Sweden has long been considered a champion of human rights in the wider world. However, a dramatic increase in immigration to Sweden in the late $20^{\text {th }}$ and early $21^{\text {st }}$ century has given Sweden's human rights concerns a new domestic focus. Sweden itself is now increasingly a multicultural society in which human rights issues are no longer mainly matters of foreign policy. Since at least the beginning of this century, Sweden has found itself having to deal with problems of equity and inclusiveness that were almost entirely outside the historical experience of what had been an extremely insular and homogenous society. Rising to the challenge, Sweden has managed to develop a strong consensus that "multiculturalism is understood as active efforts to make public institutions more inclusive and hospitable to ethnic and religious diversity." (Borevi, 2013). This essay will focus on this inclusive hospitality toward newcomers as it has manifested itself in the public institution of the school. In particular, we will describe how one school at the socio-economic margins benefits from the commitment of its leaders to ideals of multicultural inclusivity.

\section{Ringmuren Forskolan, Uppsala Sweden}

This preschool is a public school on the woodsy outskirts of Uppsala, the fourth most populous municipal area in Sweden. A preschool or Forskolan in Sweden, is for children from ages one to five. The neighborhood served by Ringmuren Forskolan has a high percentage of immigrants from a diverse mix of cultures. The parents are from Turkey, Syria, Iran, India, China, and Somalia, as well as from EU countries such as Greece, Spain, Poland, and the UK, among others. The school has between 100 and 120 children speaking 24 different languages, in addition to Swedish. Some children with autism and visual impairment are also enrolled at the school. Ringmuren Forskolan is perhaps somewhat typical of the most diverse schools in Sweden but such an extreme degree of diversity is by no means typical of Swedish schools. The principal said she hoped that through the school experience newcomers can participate in notions of freedom espoused in Swedish democracy. This democracy, she went on to say, was similar to 
what Dewey first wrote about in his book on this topic at the beginning of the progressive movement. It was based on equity.

Principals Inger Björklund and Yvonne Möller explained that they addressed the unique challenges of this school by first collaborating with Cecilia Caiman, a Stockholm University researcher. She helped them work towards the creation of a curriculum that addresses the following question: "How can we follow children's fascination, inquiry and storytelling about nature's life and death?" The principals then received the assistance of curriculum development managers Erik Andersson, an Uppsala University graduate student, and Anna-Karin Backelin, to develop a workable school plan that would attempt to answer that question. Once the school mission was formulated and submitted for review by the Uppsala local government, the actual establishment of the school could begin with the support of local government funds.

The school is founded on the idea that the recognition of children's rights can help contribute to a hopeful and sustainable future. The school's mission statement, which is entitled "Learning for Sustainable Development," sets forth the school's commitment to children's rights, democratic values and sustainability:

- The promotion of democracy and values that strengthen children's rights, inclusion and relationship creation

- Organization of the learning environment in relation to sustainability and other objectives of the curriculum

- Projecting a design approach with a focus on processes and cooperative learning

$\circ$ The right of children to a close relationship with the natural world, and the cultivation of careful actions to create sustainable habits

- A caring approach to the environment gives materials longer life

(Ringmuren Forskolan Mission Statement, 2019)

So how do these ideals manifest themselves in practice? We will outline a few distinctive characteristics of the school's unique curriculum in action.

\section{Design}

From the outside, the school building is a nondescript structure of the sort typically used for Swedish schools. It is inexpensively but solidly built and has no architectural pretentions. It is entirely utilitarian. Upon entering, the first thing one notices about the school is its carefully planned layout. Rooms flow into rooms, and certain areas are marked off for exclusive purposes. There are quiet spaces for each age group and also for teachers. These spaces suggest a strong Reggio Emilia influence. Overall the school design makes clear that children are at the center of the educational enterprise.

\section{Learning rooms}

Learning spaces are designed (aesthetically, too) for each level of development. Developmental spaces provide what research has shown to be comfortable, appropriate places for learning at each stage of a child's development. So, for one-year olds, there is a room for the senses, one with water and plants, one with an opportunity for creative play, and a room to experiment with lights of different colors. Children are free to roam the rooms of interest to them. Each room's space is small---only 3 or 4 children can enter at most. Teachers note what interests an individual child and talks to them about it, urging them to express themselves when they are ready. At the age of two, as the senses and body develop, a room offers a variety of light, sound, and sensory (sand, water, soft items) opportunities, as well as for storytelling and increased interaction with the natural environment and creative construction. By the time children are three, they are experimenting more with the outside natural environment, with the art studio, as well as with the indoor garden and atrium, where they experiment with growing things and also, observing decay. A magic room provides children with the chance to play with optical illusions (IT based) as the teacher helps them understand how these are formed. Logic and mathematics, as well as small-scale digital construction takes place here. At four, the student spends more time on reading and working in the studio and textile room. A basic understanding of science-biology physics, and chemistry - is learned, and some things related to technical-analog and digital sound and movie production are introduced. Finally, at five years old, students are using the Sustainable Room for experiments in light, growth, and the experience of the decay (death) of natural things like mushrooms or apples. This is further discussed in the communication room where language and mathematics, as well as 
pattern construction is encouraged. The day the author visited, a selection of various pipes was on a table so the children could learn about wind and where it comes from. Blowing into the tubes, one of the teachers explained, first helped them understand that the wind was also within their bodies, thus connecting the inner wind with outside nature. Finally, wind was related to the energy windmills the children sometimes see in the countryside.

\section{Teacher instruction/cooperation}

The main teacher/developers, full-time teachers, part-time helpers as well as class helpers, meet regularly to discuss the projects, problems, and outcomes of their teaching objectives. The management teachers like Erik, well schooled in pedagogy, engage the other teachers by offering them ideas for projects derived from research programs. They also work to integrate teacher-driven ideas for activities into the curriculum as it is being formed. The immediate community of parents is also welcome to participate in a number of cultural events that highlight the neighborhood's diversity. Mothers and fathers, both, could be seen at the school during the author's visit. One father was outdoors watching the four-year olds as they did a wood construction project using real hammer and nails. (Surprisingly, there were no accidents and no apparent concern that there might be). Inger explained warmly and proudly that Erik and the other development manager work hard to involve all the staff and parents democratically in decisions about the curriculum and to listen to their concerns, and that everyone has a voice in the creation of the school.

Another important inclusive action can be seen in the cloakroom where parents come to pick-up and drop off their children. Here, a mini-lending library of books is placed close to where shoes and coats are kept. This encourages sharing, and also, helps parents far from the city library to read free-of-charge books that may otherwise be difficult to obtain.

\section{Conclusion}

Many educators believe that ideally children should start their education by allowing their natural curiosity to lead them toward a love of learning in an environment of peers that is open and accepting. But education is not just about children in isolation. It is also about teachers and parents, and how they contribute to the learning environment. When they are invited to participate and contribute in an atmosphere of respect, no matter whether they are full or part-time teachers, or even helper parents, the school community benefits. In the case presented here, the inclusive hospitality and deep concern for the creation of a learning community owes much to the passion and commitment of the principals and main teachers who created a vision and a mission for their school, and then worked to build a curriculum on that foundation.

The commitment to curriculum development based on a progressive pedagogy was an impressive aspect of Ringmuren Forskolan. Equally impressive was the care teachers took to ensure that their curriculum was suited to their students and that no teacher or helper was denied a voice in generating the ideas necessary to make the school a dynamic learning place. This inclusion of different perspectives illustrates the degree that democratic values and consensus are valued in Sweden, and it is this aspect of Swedish society and culture that may be the most important value this school can pass on to its largely immigrant population of students and parents. "Each person counts," as the teachers often say. The teachers are committed to making multicultural education an inclusive education, feeling that education for a sustainable future does not make sense if it is intended only for certain groups within society, whether they are privileged or underprivileged. After all, in the end each child, whatever his or her background, inherits a shared future.

\section{References}

Borevi, K. (2010). Dimensions of Citizenship: European Integration Policies from a Scandinavian Perspective., in Bo Bengtsson, Per Strömblad and Ann-Helén Bay (eds.). Diversity, Inclusion and Citizenship in Scandinavia. Newcastle upon Tyne: Cambridge Scholars Publishing.

Borevi, K. (2013). Understanding Swedish Multiculturalism, in Debating Multiculturalism in the Nordic Welfare States. London: Springer.

Dewey, J. (1916). Democracy and Education. New York: Macmillan Press.

Essen, G. (2018). Systematiskt kvalitetsarbete. Stockholm: Text and Kultur AB.

Stoudt, A. (2021). The Reggio Emilia Approach. Retrieved May 23, 2021 from https://www.scholastic.com/teachers/articles/teaching-content/reggio-emilia-approach/ 